\title{
GAYA KEPEMIMPINAN SITUASIONAL DI PERPUSTAKAAN JARINGAN DOKUMENTASI DAN INFORMASI HUKUM KABUPATEN SLEMAN
}

\author{
Shinta Nofita Sari,S.Sos.,M.A. \& Fitri Kartika Sari,SIP.,M.A. \\ Universitas Sari Mutiara Indonesia \& Akper Karya Husada Yogyakarta \\ shintanofitas@gmail.com \& fitrikartika@yahoo.com
}

\begin{abstract}
The research was conducted in the documentation and legal Information Library (JDIH) Sleman Regency, Yogyakarta. The purpose of this study is to be able to know how to apply situational leadership styles in the JDIH library. The method used in this research is a qualitative descriptive through the case study approach. The result of this research is the library JDIH Sleman Regency, Yogyakarta its leadership style belongs to the style of situational leadership because the leader has strict characteristics, ambitious, tireless in the work but still consider his subordinate abilities. Leaders provide positive energy to subordinates in the form of encouragement, ready to help when there is a job that is not understood by his subordinate.
\end{abstract}

Keywords: Situational leadership style

\begin{abstract}
ABSTRAK
Penelitian ini dilakukan di Perpustakaan Dokumentasi dan Informasi Hukum (JDIH) Kabupaten Sleman, Yogyakarta. Tujuan dari penelitian ini yaitu untuk dapat mengetahui bagaimana penerapan gaya kepemimpinan situasional di Perpustakaan JDIH. Metode yang digunakan dalam penelitian ini yaitu deskriptif kualitatif melalui pendekatan studi kasus. Hasil dari penelitian ini yaitu Perpustakaan JDIH Kabupaten Sleman, Yogyakarta gaya kepemimpinnya termasuk kedalam gaya kepemimpinan situasional karena pemimpin memiliki karakteristik yang tegas, ambisius, tidak mengenal lelah dalam bekerja namun masih mempertimbangkan kemampuan bawahannya. Pemimpin memberikan energi postif kepada bawahan dalam bentuk memberikan semangat, siap membantu apabila ada hal pekerjaan yang tidak dipahami oleh bawahannya.
\end{abstract}

Kata Kunci : Gaya Kepemimpinan Situasional

\section{PENDAHULUAN}

Pemimpin yang baik, merupakan pemimpin yang memberi kemajuan dan keberhasilan dalam setiap organisasi yang dipimpin. Dalam struktur organisasi, pemimpin memiliki peran yang sangat penting, karena pemimpin merupakan struktur paling atas dan orang yang bertanggung jawab dalam organisasi tersebut. Setiap pemimpin memiliki gaya kepemimpinan yang berbeda beda.
Kepemimpinan juga merupakan suatu kemampuan individu untuk dapat mempengaruhi, memotivasi dan menjadikan orang lain mampu memberikan kontribusi kepada pemimpin tersebut demi keberhasilan dan efektivitas suatu organisasi. ${ }^{1}$

Gaya kepemimpinan merupakan norma perilaku yang digunakan oleh seseorang untuk mempengaruhi perilaku orang lain. Masing-masing gaya kepemimpinan memiliki 1 Gary Yuki, Kepemimpinan Dalam Organisasi (Jakarta: Indeks, 2009), 4. 
kelebihan dan kekurangan. Seorang pemimpin menerapkan gaya kepemimpinan sesuai dengan kharakteristik dan kepribadiannya. Berbagai jenis gaya kepemimpinan yang dilakukan oleh seorang pemimpin, tergantung dari sifat dan karakteristik pemimpin tersebut.

Di dalam dunia pendidikan khususnya perguruan tinggi pemimpinnya yaitu rektor. Perpustakaan yang berpengaruh dalam perguruan tinggi dipimpin oleh seorang kepala perpustakaan. Perpustakaan merupakan sumber informasi dan pengetahuan bagi pengguna. Tidak hanya itu, perpustakaan memberikan layanan, fasilitas dan berbagai jenis macam koleksi yang dapat dimanfaatkan oleh pemustaka. Berbagai kegiatan diperpustakaan dilakukan oleh pustakawan. Pustakawan bekerja sesuai dengan SOP dan tanggung jawab masing-masing yang telah disetujui oleh pimpinannya.

Pada penulisan ini, akan membahas mengenai kepemimpinan pada lembaga perpustakaan khusus. Tempat penelitian yaitu Perpustakaan Jaringan Dokumentasi dan Informasi Hukum (JDIH) Kabupaten Sleman. JDIH dilaksanakan dalam rangka meningkatkan pelayanan masyarakat untuk memenuhi kebutuhan informasi hukum. Berdasarkan Peraturan Bupati Sleman Nomor 47 tahun 2016 mempunyai tugas menyiapkan bahan publikasi dan pengelolaan dokumentasi hukum. Penyebarluasan Produk Hukum Daerah (Peraturan Daerah dan Peraturan Bupati) secara lengkap, akurat, mudah dan cepat kepada masyarakat melalui sistem JDIH untuk menata bahan dokumentasi hukum secara terpola dan teratur dengan cara mengelompokkan dalam klasifikasi yang sistematis, sehingga akan mempermudah dalam pencarian dan penemuan kembali peraturan perundang-undangan yang lengkap dan sistematis yang dapat menunjang kelancaran tugas-tugas pemerintahan, kemasyarakatan dan pembangunan di segala bidang. Selain itu, perpustakaan JDIH memiliki koleksi koleksi umum dan kolesi khusus yang dapat dimanfaatkan oleh masyarakat, para pegawai di JDIH tersebut. Koleksi tersebut ada yang dapat dipinjamkan dan ada koleksi yang hanya dapat digunakan di perpustakaan.

Perpustakaan JDIH memiliki pemimpin bernama Sumiyatun, SH.,MH dan satu anggota pustakawan. Pemimpin perpustakaan JDIH merupakan pemimpin yang tegas, ambisius dan tidak mengenal lelah dalam bekerja. Pemimpin juga memberikan energi positif kepada bawahan dalam bentuk memberikan semangat, siap membantu, mengarahkan apabila ada hal pekerjaan yang tidak dipahami, dapat memberikan masukan dalam bentuk konsultasi antara pemimpin dengan bawahan apabila ada suatu masalah baik dalam bentuk pekerjaan atau masalah lain. Dari beberapa kharakteristik pemimpin tersebut, pemimpin perpustakaan JDIH termasuk kedalam kepemimpinan situasional. Kepemimpinan situasional yaitu gaya kepemimpinan yang bersifat ideal karena karakteristiknya tegas dan disiplin namun tetap memperhatikan dan mempertimbangkan kemampuan bawahan yang dipimpin. ${ }^{2}$

Berdasarkan urian yang di jelaskan di atas, penulis tertarik untuk menulis Gaya Kepemimpinan Situasional di Perpustakaan Jaringan Dokumentasi dan Informasi Hukum Kabupaten Sleman, Yogyakarta.

\section{METODE PENELITIAN}

Metode penelitian pada penulisan itu yaitu deskriptif kualitatif melalui pendekatan studi kasus. Peneliti melakukan observasi langsung ke perpustakaan JDIH Kabupaten Sleman dengan cara mengamati dan melakukan wawancara dengan pustakawan.

\section{KAJIAN LITERATUR}

\section{Kepemimpinan}

a. Pengertian Kepemimpinan

Kepemimpinan yaitu suatu proses dalam mendorong dan membantu orang 
lain dalam bekerja dengan antusias dan mencapai tujuan. Peran utama seorang pemimpin yaitu mempengaruhi dan menggerakkan bawahan atau orang lain untuk dapat mencapai tujuan yang telah ditetapkan. ${ }^{3}$ Pria dan wanita memiliki potensi sama untuk dapat menjadi seorang pemimpin, dari sudut pandang kepemimpinan, namun perbedaan tersebut mempengaruhi pola kepemimpinan. ${ }^{4}$

Kepemimpinan dapat dikatakan efektif apabila dapat berjalan sesuati dengan fungsinya. Fungsi kepemimpinan berkaitan dengan sitausi sosial yang terjadi pada suatu organisasi. adapun fungsi kepemimpinan meliki 2 dimensi yaitu pertama dimensi yang berhubungan dengan tingkat kemampuan untuk mengarahkan, kedua dimensi yang berhubungan dengan tingkat dukungan dalam melakukan pekerjaan yang sesuai dengan kebijakan dan keputusan pemimpin. ${ }^{5}$

Dari beberapa pengertian diatas, maka dapat disimpulkan bahwa kepemimpinan merupakan suatu kemampuan dalam hal mempengaruhi, menggerakkan, mendorong, mengendalikan, mengarahkan orang lain atau bawahan untuk melakukan suatu pekerjaan atas kesadarannya dan berkontribusi dalam mencapai tujuan.

b. Karakteristik Kepemimpinan

Karakteristik kepemimpinan menurut David C Kozak dalam David I Bartocci yaitu: ${ }^{6}$

3 Mas'ud Said, Kepemimpinan Pengembangan Organisasi Team Building dan Perilaku Inovatif (Malang: UIN Maliki Press, 2010), 283

4 Tikno Lensufiie, Leadership untuk professional dan mahasiswa (Jakarta: Esensi, 2013), 96

5 Hadari Nawwi, Kepemimpinan Mengefektifkan Organisasi (Yogyakarta:Gadjah Mada University Press, 2003), 35.

6 David C. Kozak, Leadership, (Gannon University Magazine: Winter, 1998), 4.

\begin{tabular}{|l|l|l|}
\hline \multicolumn{1}{|c|}{ Intelligence } & \multicolumn{1}{|c|}{ Personality } & \multicolumn{1}{c|}{ Abilities } \\
\hline Pertimbangan & Adaptasi & $\begin{array}{l}\text { Menawarkan } \\
\text { Diri Kerja Sama }\end{array}$ \\
\hline Ketegasan & Kewaspadaan & Kerja Sama \\
\hline Pengetahuan & Kreativitas & $\begin{array}{l}\text { Populer dan } \\
\text { Wibawa }\end{array}$ \\
\hline $\begin{array}{l}\text { Kelancaran } \\
\text { Komunikasi }\end{array}$ & $\begin{array}{l}\text { Kepercayaan } \\
\text { Diri }\end{array}$ & Ramah \\
\hline & Kontrol Emosi & Sifat Sosial \\
\cline { 2 - 3 } & Kebebasan & Bijaksana \\
\hline
\end{tabular}

Tabel 1: Karakteristik Diri Dari

Kepemimpinan

Kepemimpinan menurut William E. Rosenbach and Robert L. Taylor perlu memiliki beberapa kharakteristik sebagai berikut: ${ }^{7}$

1) Kecerdasan untuk fokus dalam mencapai tujuan dan hasil

2) Mudah beradaptasi dengan lingkungan

3) Bergerak sesuai dengan arahan / prioritas

4) Menularkan motivasi bagi pengikut / bawahan mengenai komptensi dan kepercayaan diri

5) Energy, berani, gigih

6) Karakter yang jujur, bijaksana

7) Berani mengambil resiko

8) Memahami kemampuan diri.

c. Gaya kepemimpinan

Gaya kepemimpinan merupakan cara yang digunakan oleh pemimpin dalam mempengaruhi pengikutnya. Gaya kepemimpinan dapat dianggap modalitas karena sukses dan gagalnya keberhasilan seseorang dalam memimpin ditentukan oleh kualitas kepemimpinan yang dimilikinya. ${ }^{8}$ Gaya kepemimpinan yaitu sekumpulan ciri yang digunakan oleh pimpinan

7 William E. Rosenbach and Robert L. Taylor, Contemporary Issues in Leadership (Boulder, CO: Westview Press, 1993), 5.

8 Cindy Molantong, dkk, "Gaya Kepemimpinan Kepala Perpustakaan Terhadap Motivasi Kerja Pegawai di Perpustakaan Arsip dan Dokumentasi Kota Kotamobagu. E-journal “Acta Diurna” Vol IV, No.3. Th 2015. 
untuk mempengaruhi bawahan agar sasaran organisasi tercapai atau dapat dikatakan bahwa gaya kepemimpinan adalah pola perilaku dan strategi yang disukai dan sering pula diterapkan oleh pemimpin.

Gaya kepemimpinan lain didefinisikan sebagai teknikteknik gaya kepemimpinan dalam mempengaruhi bawahannya dalam melaksanakan tugasnya berdasarkan kewenangan dan kekuasaan untuk melaksanakan fungsi-fungsi manajemen ${ }^{9}$ Gaya kepemimpinan merupakan sebuah cara seorang pemimpin untuk bertindak. Gaya kepemimpinan dapat mencakup ${ }^{10}$ :

1) Faktor fisik meliputi bahasa tubuh, nada bicara atau suara, kontak mata, dan kata-kata yang digunakan.

2) Faktor karakteristik seperti kerendahan hati, kecerdasan, atau intelektualitas.

Terdapat dua faktor gaya kepemimpinan, yaitu ${ }^{11}$ :

1) Gaya yang berorientasi pada tugas, seperti:

a) Pemimpin memberikan petunjuk kepada bawahan

b) Pemimpin selalu mengadakan pengawasan secara ketat terhadap bawahan

c) Pemimpin meyakinkan kepada bawahan bahwa tugas-tugas harus dilaksanakan sesuai dengan keinginannya.

d) Pemimpin lebih menekankan kepada pelaksanaan tugas daripada pembinaan dan pengembangan bawahan

10 Kumaran, Maha, Leadership In Libraries: a focus in etnic minority librarians (Oxford: Chandos Publishing. 2012)

11 Ari Krisnawulan, Analisis Gaya Kepemimpinan Situsional Manager pada Divisi Logistik. (Depok: PT. Dunkindo Lestari. 2005).
2) Gaya yang berorientasi pada karyawan/pegawai:

a) Pemimpin lebih bersifat kekeluargaan, saling percaya dan kerja sama, saling menghormati di antara sesame anggota kelompok

b) Pemimpin lebih memberikan motivasi daripada memberikan pengawasan kepada bawahan

c) Pemimpin melibatkan bawahan dalam pengambilan keputusan

\section{Kepemimpinan Situasional}

a. Pengertian Gaya Kepemimpinan Situasional

Gaya kepemimpinan situasioanl disebut sebagai gaya kepemimpinan yang ideal karena karakteristik gaya kepemimpinan ini memiliki sifat yang tegas dan disiplin akan tetapi masih mempertimbangkan dan memahami kemampuan bawahannya atau orang-orang yang dipimpinnya dalam suatu kegiatan atau organisasi. ${ }^{12}$ Kepemimpinan situasional ini harus memiliki tindakan yang terbaik berdasarkan situasi yang sedang dihadapi, dan gaya kepemimpinan ini tergantung pada situasi yang berlainan ${ }^{13}$.

Teori kepemimpinan situasional ini dikembangkan oleh Robert House yang mengemukakan pada teori pengharapan dalam motivasi yang mengatakan bahwa seseorang akan termotivasi oleh dua harapan berupa kemampuannya untuk mengerjakan suatu tugas dan rasa percayanya bahwa dia dapat menyelesaikan tugas tersebut

\footnotetext{
12 Miftahunnisa Igiriza, Pengaruh Gaya Kepemimpinan Situasional dan Motivasi Terhadap Kinerja Pegawai di Dinas Perpustakaan dan Kearsipan Kota Yogyakarta (Yogyakarta: UIN Sunan Kalijaga, 2017), 21

13 Paul Hersey and Blanchard, Management of Organizational Behaviour, $5^{\text {th }}$ ed (Englewood Cliffs: Prentice Hall, 1998).
} 
dengan baik ${ }^{14}$.

Seorang pemimpin yang efektif dalam kepemimpinan situasional sebisa mungkin dapat memahami dinamika situasi dan menyesuaikan kemampuannya dengan dinamika situasi yang ada. Penyesuaian gaya kepemimpinan ini adalah kemampuan menentukan ciri kepemimpinan dan perilaku karena tuntutan situasi tertentu.

b. Gaya Kepemimpinan Situasioanal

Terdapat empat bentuk gaya kepemimpinan situasional, yaitu: ${ }^{15}$

1) Gaya kepemimpinan situasional Instruktif (Telling)

Instruktif yaitu suatu tugas yang diberikan oleh seorang atasan kepada bawahan, dimana bawahan perlu bertindak atau menahan diri untuk bertindak dalam suatu keadaan tertentu. ${ }^{16}$ Pada gaya ini, pemimpin memberitahu bawahan mengenai apa saja yang akan dilakukan, dimana dan bagaimana cara melakukan suatu pekerjaan, dan pemimpin menentukan struktur / peran bawahannya ${ }^{17}$

2) Gaya kepemimpinan situasional Konsultatif (Selling)

Konsultatif pada gaya kepemimpinan ini memberi kesempatan pemimpin berdialog atau berdiskusi dengan bawahannya dalam melaksanakan tugas. Bawahan dapat mengajukan pertanyaan sehingga tercipta komunikasi dua arah. ${ }^{18}$ Gaya kepemimpinan ini ditandai dengan

14 Sinollah, "Pengaruh Gaya Kepemimpinan Situasional terhadap Motivasi Kerja Karyawan" CV. Duta Bangsa Pasuruan. Jurnal OTONOMI Vol. 10, No.2. 2010

15 Triantoro Safaria, Kepemimpinan (Yogyakarta: Graha IImu, 2004), 71.

16 Moekijat, kamus Manajemen (Bandung: Mandar Maju, 1990), 237.

17 Paul Hersey, Ibid., 177

18 Ibid., 178 adanya komunikasi dialogis dari pemimpin, pemimpin meminta diberi masukan atau saran sebelum membuat keputuasan. Pemimpin juga memberikan dukungan sosio-emosional agar bawahan dapat bertanggung jawab dalam pekerjaannya. ${ }^{19}$

3) Gaya kepemimpinan situasional Partisipatif (Participating).

Partisipatif yaitu keterlibatan baik rokhaniah maupun perasan dari seorang atasan dalam suatu organisasi untuk memikul / mengambil bagian tanggung jawabnya. ${ }^{20}$ Pemimpin pada gaya ini tidak lagi memberitahu atau menjelaskan apa yang harus dilakukan, dimana melakukan atau bagaimana cara melakukan pekerjaan. Pada gaya ini, pemimpin melakukan diskusi, memberikan dukungan dan memfasilitasi dalam melaksanakan tugas..$^{21}$ Gaya kepemimpinan juga ditandai dari kerjasama antara pemimpin dengan bawahan dalam pengambilan keputuasan dengan cara melalui diskusi dan memberikan kemudahan akses informasi penting. Pemimpin selalu melibatkan bawahan untuk berpatispasi dalam setiap aktivitas kerja sehingga bawahan dapat semakin berkembang lebih baik. ${ }^{22}$

4) Gaya kepemimpinan situasional Delegatif (Delegating)

Delegatif yaitu tindakan mempercayakan bagian pekerjaan seorang atasan yang diselesaikan oleh bawahan. ${ }^{23}$ Pada gaya

\footnotetext{
19 Triantoro Safaria, Ibid., 71

20 Moekijat, Ibid., 365

21 Paul Hersey, Ibid., 178

22 Triantoro Safaria, Ibid., 73

23 Moekijat, Ibid., 115
} 
kepemimpinan ini, pemimpin hanya mengamati apa yang terjadi. Bawahan diberi kesempatan untuk mengambil tanggung jawab dan memberi kebebasan dalam melaksanakan tugas, karena sudah dianggap mampu sehingga tugas tersebut dapat dikerjakan dengan efektif dan efisien. ${ }^{24}$

\section{PEMBAHASAN}

Keberhasilan sebuah organisasi bergantung pada bagaimana kepemimpinannya. Jika pemimpin mampu menjalankan tugasnya dengan baik, maka keberhasilan sebuah organisasi akan tinggi. Gaya kepemimpinan setiap pemimpin itu berdeda-beda. Hal ini bisa saja karena lingkungan, tempat kerja, dan kepribadian memiliki jiwa kepemimpinan.

Perpustakaan di Jaringan Dokumentasi dan Informasi Hukun Kabupaten Sleman memiliki pemimpin yang bernama Sumiyatun, SH., MH. Menurut pengamatan dan wawancara yang telah dilakukan oleh peneliti bersama pustakawan JDIH yaitu Umi Uswatun Hasanah. Umi sebagai pustakawan menjelaskan bagaimana gaya kepemimpinan perpustakaan di JDIH tersebut.

Adapun gaya kepemimpinan perpustakaan Jaringan Dokumentasi dan Informasi Hukum Kabupaten Sleman yaitu:

\section{Gaya Instrukstif (Telling)}

a. Pemimpin perpustakan JDIH selalu memberitahu apa saja tugas yang dianggap penting untuk dilakukan oleh bawahan, pemimpin meminta bawahan untuk mengutamakan pekerjaan tersebut seperti laporan yang dibutuhkan dalam waktu mendesak dan harus dilampirkan pada data tertentu.

b. Apabila bawahan tidak memahami atau tidak mengerti mengenai pekerjaan yang diberikan pimpinan, pemimpin memberikan arahan terhadap pekerjaan
tersebut.Akan tetapi, apabila pemimpin tidak berada di tempat, bawahan dapat menghubungi pemimpin melaui HP.

\section{Gaya Konsultatif (Selling)}

a. Pemimpin JDIH selalu terbuka dan memberikan kesempatan bawahannya untuk memberikan masukan mengenai pekerjaan dan kegiatan yang dilakukan di perpustakaan. Pemimpin merasa bangga, apabila bwahannya dapat memberikan ide dan kreatifitas yang bersifat membanggun.

\section{Gaya Partisipatif (Participating)}

a. Pemimpin JDIH merupakan pemimpin yang energik, untuk itu pemimpin juga selalu memberikan semangat kepada bawahannya apabila melihat bawahan merasa mengantuk, malas dalam bekerja. Pemimpin bahkan memberikan makanan ringan untuk bawahan, agar bawahannya bisa semangat lagi dalam bekerja.

b. Pemimpin JDIH tidak selalu memberikan tugas pekerjaan di luar lingkungan JDIH. Untuk kegiatan pelatihan perpustakaan, bawahan selama bekerja belum pernah mengikuti, akan tetapi apabila ada undangan acara dinas, bawahan pernah ikut serta bersama pimpinan.

c. Selama bekerja di perpustakaan JDIH, pimpinan belum pernah memberikan reward dalam bentuk apapun. Akan tetapi, bawahan merasa reward tersebut dalam bentuk menghargai bawahan

\section{Gaya Delegatif (Delegating)}

a. Pimpinan selalu memberitahu bawahan untuk dapat bertanggung jawab penuh terhadap pekerjaan.

b. Pimpinan tidak pernah mengamati bawahan selama bekerja, karena pimpinan merasa yakin dan percaya bahwa bawahannya memiliki kemampuan dan bertanggung jawab dalam bekerja. 


\section{PENUTUP}

Dari hasil pembahasan yang telah dijelaskan, gaya kepemimpinan Perpustakaan di Jaringan Dokumentasi dan Informasi Hukum Kabupaten Sleman termasuk kedalam gaya kepemimpinan situasional karena pemimpin memiliki karakteristik yang tegas, ambisius, tidak mengenal lelah dalam bekerja namun masih mempertimbangkan kemampuan bawahannya. Pemimpin memberikan energi positif kepada bawahan dalam bentuk memberikan semangat, siap membantu apabila ada hal pekerjaan yang tidak dipahami oleh bawahannya, dll

Ada 4 gaya kepemimpinan situasioanal yang dilakukan oleh pemimpin Perpustakaan Jaringan Dokumentasi dan Informasi Hukum yaitu Gaya Instrukstif (Telling), Gaya Konsultatif (Selling), Gaya Partisipatif (Participating), Gaya Delegatif (Delegating)

\section{DAFTAR PUSTAKA}

Igiriza, Miftahunnisa. Pengaruh Gaya Kepemimpinan Situasional dan Motivasi Terhadap Kinerja Pegawai di Dinas Perpustakaan dan Kearsipan Kota Yogyakarta. Yogyakarta: UIN Sunan Kalijaga, 2017

Kozak, David C.. Leadership. Gannon University Magazine: Winter, 1998.

Krisnawulan, Ari. Analisis Gaya Kepemimpinan Situsional Manager pada Divisi Logistik. Depok: PT. Dunkindo Lestari. 2005.

Lensufiie, Tikno. Leadership untuk professional dan mahasiswa. Jakarta: Esensi, 2013.

Maha, Kumaran. Leadership In Libraries: a focus in etnic minority librarians. Oxford: Chandos Publishing. 2012.

Moekijat. Kamus Manajemen. Bandung: Mandar Maju, 1990.
Molantong, Cindy, dkk. Gaya Kepemimpinan Kepala Perpustakaan Terhadap Motivasi Kerja Pegawai di Perpustakaan Arsip dan Dokumentasi Kota Kotamobagu. E-journal “Acta Diurna” Vol IV, No.3. Th 2015.

Nawi, Hadari. Kepemimpinan Mengefektifkan Organisasi. Yogyakarta:Gadjah Mada University Press, 2003.

Paul Hersey and Blanchard. Management of Organizational Behaviour, $5^{\text {th }}$ ed. Englewood Cliffs: Prentice Hall, 1998.

Safaria, Triantoro. Kepemimpinan (Yogyakarta: Graha Ilmu, 2004), 71.

Said, Mas'ud.Kepemimpinan Pengembangan Organisasi Team Building dan Perilaku Inovatif. Malang: UIN Maliki Press, 2010.

Sinollah. Pengaruh Gaya Kepemimpinan Situasional terhadap Motivasi Kerja Karyawan" CV. Duta Bangsa Pasuruan. Jurnal OTONOMI Vol. 10, No.2. 201

William E. Rosenbach and Robert L. Taylor. Contemporary Issues in Leadership. Boulder, CO: Westview Press, 1993.

Yuki, Gary. Kepemimpinan Dalam Organisasi. Jakarta: Indeks, 2009. 